\section{А.В. Молчанов,}

ФАС России,

МГЮА им. О.Е. Кутафина,

г. Москва

\section{Развитие правового института торгов в рамках конкурентного права}

\begin{abstract}
Аннотация
Регулирование отношений, связанных организацией и проведением торгов исключительно нормами гражданского права и гражданским законодательством, невозможно, поскольку вопросы обеспечения конкуренции носят публичный характер, направлены на обеспечение публичного интереса, относящегося к основам конституционного строя России, и потому требуют публично правовой регламентации. Учитывая значение торгов для обеспечения конкуренции, более эффективно развивать как сам правовой институт торгов в сфере комплексной отрасли конкурентного права, так и законодательство о торгах, как его внешнее проявление, в сфере антимонопольного законодательства.
\end{abstract}

Ключевые слова: торги, развитие и обеспечение конкуренции, комплексный правовой институт, конкурентное право.

\title{
Development of legal institute of the auction within the competitive right
}

\section{A. V. Molchanov,}

FAS Russia,

Kutafin Moscow State Law University (MSAL),

Moscow

\begin{abstract}
Annotation
Regulation of relations connected with the organization and holding of tenders exclusively by the norms of civil law and civil legislation is impossible, since the issues of ensuring competition are of a public nature, aimed at ensuring public interest, which is the basis of the constitutional system of our state, and therefore require public legal regulation. Taking into account the importance of tenders for ensuring competition, it is more effective to develop both the legal institution of tenders in the sphere of complex branch of competition law and the legislation on tenders, as its external manifestation, in the sphere of antimonopoly legislation.
\end{abstract}

Keywords: tenders, development and ensuring of competition, complex legal institution, competition law.

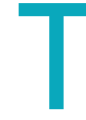

радиционно торги рассматриваются как способ заключения договора и, вследствие этого, как институт гражданского права. Несмотря на то, что в Гражданском кодексе Российской Федерации' (далее - ГК РФ), да и в ином федеральном законодательстве отсутствует легальное определение понятия торгов, способ заключения договора относится к регулированию торгов, исходя из совокупности признаков, которые определены в ст. 447-449' ГК РФ.

В этом небольшом количестве статей, содержащихся в гл. 28 «Заключение договора» ГК РФ, содержатся общие правила относительно заключения договора на торгах, общие положения об организации и проведении торгов, описание наиболее

\footnotetext{
См.: Гражданский кодекс Российской Федерации, ст. 447-4491.
} 
Развитие правового института торгов в рамках конкурентного права

распространенных форм торгов (аукцион и конкурс), общие основания признания торгов недействительными и последствия такого признания для участников соответствующих правоотношений.

Однако вслед за бурным развитием торгов в нашей действительности указанные положения ГК РФ не претерпели существенных изменений, за исключением ряда уточнений. Гражданско-правовое регулирование ограничивается в регулировании торгов вопросами процедурных особенностей заключения договора.

И с точки зрения гражданского права это естественно. Гражданско-правовое значение торгов действительно заключается в том, что торги представляют собой особую процедуру или сложный юридический состав приобретения гражданских прав и обязанностей.

Так, еще Д.И. Мейер отмечал относительно продажи с публичных торгов, что такая продажа представляет ту особенность, что рассчитывает на соревнование между лицами, желающими купить продаваемое имущество, ради чего именно и производится публично. Но очевидно, тут нет никакого обстоятельства, которое влияло бы на существо купли-продажи: как скоро является наиболее выгодный покупатель, то с ним только и заключается договор [1].

Развитие хозяйственных отношений, основанных на частной собственности и конкуренции между самостоятельными хозяйствующими субъектами, привело между тем к существенному росту интереса к торгам и необходимости развития их правового регулирования.

Причем само развитие правового института торгов в большей или меньшей степени происходило на разных этапах именно вследствие активизации хозяйственной деятельности, основанной на товарно-денежных отношениях. Между этими явлениями есть прямая зависимость, которая прослеживается в историческом аспекте.

Еще в 1722 г. Петром I был утвержден «Регламент об управлении адмиралтейства и верфи о должностях Колегии адмиралтейской и прочих всех чинов при адмиралтействе обретающихся» (далее - Регламент) [2], который включал положения, устанавливающие специальную процедуру определения поставщиков и подрядчиков, которая по своим признакам вполне соответствует современному понятию торгов.

Эта процедура предусматривала порядок извещения о поиске подрядчиков, требования к срокам извещения и описание предмета подряда, порядок непосредственно торга. Не менее важно, что в Регламенте были установлены требования к добросовестности участников: «в подряд никому не отдавать ничего, пока оный подрядчик не освидетельствован будет в Колегии, можно ему в том подряде верить».

Следующим в России значимым документом, регулирующим правила организации и проведения торгов, стало Положение об обязательствах, заключаемых с торгов между казною и частными людьми по подрядам, постав- кам, по содержанию оброчных статей и продажам казенных движимых имуществ [3].

В Положении предусматривалось не только регулирование процедуры торга, но также содержались запреты соглашений участников торгов.

Нормы о запрете антиконкурентных соглашений на торгах, содержащиеся в Положении 1830 г., можно с уверенностью отнести к первым антимонопольным требованиям в российском законодательстве, позже обеспеченным мерами уголовной ответственности в Уложении о наказаниях уголовных и исполнительных 1845 г., ст. 1619 которого устанавливала, что «Кто, при продаже недвижимого или движимого имущества с публичного торга, или при торгах на подряды и поставки или откупы, склонит других подарками, обещаниями или иным образом, не участвовать в сих торгах, тот за сие подвергается денежному взысканию от пятидесяти до пятисот рублей».

Таким образом, развитие в отечественном праве норм, направленных на обеспечение конкуренции, было непосредственно связано с развитием правового регулирования торгов. И это не случайно, поскольку сами торги представляют собой явление, тесно связанное со свободной и справедливой конкуренцией, обеспечивающей наиболее эффективный результат заключения различного рода сделок между участниками гражданско-правовых отношений, в том числе и сделок между государством и частными субъектами.

Поиск оптимального (наиболее выгодного сторонам) предложения при заключении договора является разумной и логичной целью поведения участников гражданско-правового оборота.

В этой связи возможность оценки наибольшего числа предложений или предложение своих условий предоставления объектов гражданских прав в условиях соревнования с другими участниками обеспечивает повышение эффективности для заинтересованной стороны.

На современном этапе значение торгов для системы экономических отношений сложно переоценить. Торги стали стандартной формой участия государства и муниципальных образований в экономических отношениях, обеспечивая равный доступ всех потенциальных участников к объектом публичной собственности и публичным финансам. Но и в тех сферах, где сторонами сделок выступают исключительно частные субъекты, торги также занимают все большее место, являясь инструментом повышения эффективности ведения хозяйственной деятельности.

В современной России бурное развитие правового регулирования торгов проходит в отраслевом законодательстве: законодательстве о закупках для государственных и муниципальных нужд, земельном, лесном и водном законодательстве, законодательстве о несостоятельности (банкротстве), законодательстве в области связи и так далее. 
Торги уже давно перестали быть только способом заключения договора.

Как отмечает О. А. Беляева, следует констатировать, что институт торгов в наши дни приобрел межотраслевой характер: с определенными особенностями он применяется не только в гражданском праве, но и за его пределами. Торги - это универсальная модель приобретения различного рода прав [4].

Такое развитие институт торгов получил благодаря своим признакам.

Первым таким признаком является соперничество участников торгов, претендующих на приобретение гражданских прав и обязанностей, а вторым - обязательность для организатора (заказчика) торгов и победителя установления таких гражданских прав и обязанностей в результате торгов, обеспечиваемая неблагоприятными последствиями в случае уклонения организатора торгов (заказчика) или победителя от оформления правоотношений, на которые были направлены торги.

Таким образом, свойством торгов является соперничество или конкурентный характер.

Именно поэтому, отмечая значение торгов, М.И. Брагинский и В.В. Витрянский так определяют их: «торги представляют собой один из способов заключения договоров, который тесно связан с основными законами свободного рынка, и выражают их наиболее последовательно» [5].

Л.Ф. Гатаулина, оценивая значение торгов, приходит к выводу, что именно торги позволяют максимально использовать механизм конкуренции и состязательности участников, достигать наиболее выгодных результатов, выдвигая более жесткие требования и условия по гарантиям исполнения, что и отвечает юридической природе торгов [6].

Торги на современном этапе развития экономических отношений являются не только универсальным способом приобретения прав, но и универсальным способом обеспечения конкуренции между участниками товарного рынка.

В целях обеспечения конкуренции в настоящее время законодателем введены публично-правовые ограничения в виде обязательности торгов, ограничивающие права участников гражданского оборота, но в интересах равенства прав участников таких отношений в целом (например, положения ст. $17^{1}$ Федерального закона «О защите конкуренции»² (далее - Закон о защите конкуренции) в части обязательности торгов при передаче в пользование государственного имущества, положения ст. 110 Федерального закона «О несостоятельности (банкротстве)»³ относительно продажи имущества долж-

\footnotetext{
2 См..: Федеральный закон «О защите конкуренции», ст. 171.

3 См.: Федеральный закон «О несостоятельности (банкротстве)», Ст. 110 .
}

ника и др,); предусмотрены специальные антимонопольные требования, нарушение которых связано с ограничением конкуренции (например, ст. 17 Закона о защите конкуренции, ст. 17 Закона РФ «О недрах» ${ }^{4}$ и так далее; специальные полномочия по контролю за обеспечением конкуренции при проведении торгов предоставлены специальному административному органу - Федеральной антимонопольной службе (ст. $18^{1}$ Закона о защите конкуренции - в части процедуры рассмотрения жалоб участников торгов, и ч. 4 ст. 17 того же Закона — в части права антимонопольного органа на обращение с исками в суд).

Проведенный анализ показывает, что институт торгов, зародившись в гражданском праве, вследствие востребованности для целей обеспечения защиты конкуренции, «вышел» за пределы гражданского права.

Регулирование отношений, связанных организацией и проведением торгов исключительно нормами гражданского права и гражданского законодательства, невозможно, поскольку вопросы обеспечения конкуренции носят публичный характер, направлены на обеспечение публичного интереса, заложенного в основу конституционного строя нашего государства, и потому требуют публично правовой регламентации.

Такая совокупность правовых норм сложилась в актах публично-правового регулирования: Закон о защите конкуренции в первую очередь, Закон о приватизации государственного и муниципального имущества, Закон о недрах и так далее.

Объективированную в таких актах федерального законодательства систему норм в совокупности с нормами гражданского кодекса (ст. 447-4491 ГК РФ) можно определить как комплексный правовой институт торгов, включающий частные и публичные нормы права.

Таким образом, развитие правового института торгов является тем самым примером формирования комплексного правового института, объективная потребность регламентации которого связана с развитием рыночных отношений, основанных на частной собственности, свободе договора и конкуренции.

Постепенно накапливая специфику правового регулирования, соответствующая группа отношений, связанных с организацией и проведением торгов, набрала ту самую «критическую массу», когда межотраслевой ее характер, не укладывающийся исключительно в сферу частно-правового регулирования, уже не вызывает вопросов. Больше того, ценность этих отношений для государственного устройства приводит к еще большему укреплению публично-правовой регламентации и созданию публичноправовых механизмов обеспечения законности.

Наряду с такими правовыми институтами, как пресечение и недопущение монополистической деятельности

\footnotetext{
4 См.: Закон РФ «О недрах», ст. 17.
} 
Развитие правового института торгов в рамках конкурентного права

и недобросовестной конкуренции, а также антиконкурентных действий органов власти, комплексный правовой институт торгов стал в основе формирования на современном этапе отрасли конкурентного права.

С. А. Пузыревский, говоря об отраслевой самостоятельности конкурентного права, отмечает, что юридическое равенство участников гражданских правоотношений, при наличии экономического неравенства хозяйствующих субъектов на товарном рынке, превращается в полную фикцию и не может быть реализовано. Мерами гражданско-правового регулирования указанную ситуацию в полной мере исправить невозможно. Поэтому для обеспечения подлинного равенства участников рыночных отношений включаются механизмы публично-правового регулирования, содержащиеся в системе антимонопольного законодательства [7].

Развитие публично-правовых основ в регулировании отношений, связанных с организацией и проведением торгов, признание за торгами как правовым институтом функции обеспечения экономической конкуренции как публичного блага в полной мере отражает процесс этого включения публично-правового механизма регулирования в сфере гражданско-правовых отношений.

В теории права все случаи возникновения новых отраслей права, по мнению части специалистов, сводятся к двум основаниям: 1) распространение правовой регламентации на ту часть социальной действительности, которая ранее не была объектом правового регулирования; 2) «отпочкование» от одной или нескольких отраслей права взаимосвязанной совокупности норм (правовых институтов), приобретших качественно новые свойства [8].

Исследуя вопросы комплексных правовых институтов, С.В. Поленина приходит к выводу о том, что в процессе «специализации» «пограничных» институтов нередко наступает момент, когда число «материнских» и «заимствованных» черт как бы уравновешивается, становится почти равновеликим. Сохраняясь длительное время, такая «мутация» может принять стойкий характер, постепенно углубляясь и расширяясь, придавая пограничному институту новые качестве и свойства. Этот вариант развития «пограничных» правовых институтов и приводит к появлению в дальнейшем новой отрасли права [9].

Признавая удвоение структуры права, включающей основные (первичные) и комплексные (вторичные) отрасли права, С. С. Алексеев указывал, что использование категории комплексной отрасли права «позволяет осветить механизм воздействия на систему права субъективного фактора, развития законодательства» [9].

Таким образом, формирование комплексных правовых институтов, К которым, в частности, относится институт торгов, может рассматриваться как одно из направлений формирования комплексных отраслей права. Эти процессы в первую очередь происходят вследствие развития социально-экономических отношений. Так, развитие института торгов в дореволюционный период было связано с промышленной революцией, развитием товарно-денежных капиталистических отношений, повышением значения правовой защиты частной собственности и охраны конкуренции. В настоящее время резкая потребность в правовой регламентации торгов связана с переходом от административно-командной системы хозяйствования к рыночным отношениям и провозглашением конкуренции как одной из основ конституционного строя. С другой стороны, эти процессы связаны с субъективным фактором - развитием законодательства.

Вместе с тем нельзя не признать, что формирование комплексного правового института торгов, сочетающего частно-правовые и публично-правовые положения, еще не завершено. Отраслевая направленность развития законодательства, регулирующего торги в разных сферах, приводит к разобщенности правовых норм о торгах, в некоторых случаях к дублированию, разному качественному уровню правового регулирования: от детальной, отвечающей современным требованиям регламентации электронных торгов в сфере закупок, до практически мизерного регулирования этих вопросов в законодательстве о рекламе.

В Докладе о состоянии конкуренции в Российской Федерации за 2017 г. ФАС России отмечает, что случаи и порядок проведения торгов в настоящее время регламентируются более чем 50 нормативными правовыми актами Российской Федерации 5 .

Согласно позиции ФАС России, порядок организации и проведения торгов зависит от собственника имущества или обладателя имущественных прав, что в отдельных случаях приводит к многократному увеличению количества нормативных правовых актов, регламентирующих торги в отношении одного и того же вида имущества, имущественных прав или природных ресурсов в зависимости от их местонахождения.

При этом следует отметить, что такие нормативные акты предполагают отдельные, отличающиеся друг от друга порядки организации и проведения процедур торгов, предусматривающие:

- определенные способы и сроки информационного обеспечения торгов, например, в различных средствах массовой информации или на сайтах в сети Интернет;

- специальные порядки подачи заявок на участие в торгах, в том числе предусматривающие различные требования к составу и оформлению документов, представляемых претендентами на участие в торгах при подаче заявок;

5 Cм.: https://fas.gov.ru/documents/658027 (Дата обращения: 20.01.2019) 
- особенности допуска или недопуска к участию в торгах, предполагающие специальные требования к участникам торгов, основания для отказа в допуске к торгам;

- различные порядки заключения договоров по результатам торгов, предполагающие, например, существенно отличающиеся сроки заключения договоров.

Такое многообразие процедур проведения торгов, а также непрозрачность их проведения негативно сказываются на развитии конкуренции и эффективности вовлечения в хозяйственный оборот государственного и муниципального имущества, имущественных прав и природных ресурсов и, более того, способствуют развитию коррупции.

При этом большинство нормативных правовых актов, регулирующих процедуры торгов, не предусматривают их проведение в электронной форме на электронных площадках, что в существенной степени сужает круг участников торгов в связи с территориальной удаленностью отдельных субъектов Российской Федерации и невозможностью обеспечения доступности прозрачности процедур торгов в масштабах страны.

В Докладе о состоянии конкуренции в Российской Федерации за 2017 г. указывалось на наличие планов ФАС России совместно с Минэкономразвития России продолжить планомерную работу по реализации концепции унифицированных торгов.

Реализация этих планов нашла свое отражение в Плане мероприятий («дорожной карте») по развитию конкуренции в отраслях экономики российской Федерации и переходу сфер естественных монополий из состояния естественной монополии в состояние конкурентного рынка на 2018-2020 гг., утвержденном распоряжением Правительства Российской Федерации от 16.08.2018 № 1697-p $p^{6}$.

Так, дважды в отношении сфер природных ресурсов и рыбохозяйственного комплекса в плане мероприятий говорится о таком мероприятии, как унификация торгов путем принятия федерального закона, направленного на установление единой унифицированной процедуры предоставления соответствующих прав в форме электронного аукциона.

Все этого говорит еще об одном существенном признаке обособления правового института торгов - признаке функциональном, отражающем направления государственной политики и функций государства в соответствующей сфере.

\footnotetext{
Распоряжением Правительства Российской Федерации от 16.08.2018 № 1697-р «Об утверждении Плана мероприятий («дорожной карты») по развитию конкуренции в отраслях экономики российской Федерации и переходу сфер естественных монополий из состояния естественной монополии в состояние конкурентного рынка на 2018-2020 гг. (См.: Справочно-правовая система КонсультантПлюс. Дата обращения: 20.01.2019).
}

Именно такое функциональное обособление, учитывающее основное значение торгов - обеспечение конкуренции, позволяет более эффективно развивать как сам правовой институт в сфере комплексной отрасли конкурентного права, так и законодательство о торгах, как его внешнее проявление.

Дальнейшая судьба этого правового института будет зависеть от законодателя, поскольку определение «прописки» соответствующих норм имеет немаловажное значение.

На наш взгляд, положения, направленные на обеспечение и защиту конкуренции при проведении торгов, не могут быть включены в ГК РФ, следовательно, они могут быть унифицированы в рамках той отрасли законодательства, цель и предмет регулирования которого наиболее отвечают цели правового регулирования торгов на современном этапе.

Учитывая, что торги направлены на обеспечение состязательности и конкуренции участников гражданско-правовых отношений, то совершенно очевидно, что именно антимонопольное законодательство должно определить необходимый и достаточный объем регулирования этих процедур.

Решение этого вопроса имеет принципиальный характер с точки зрения целеполагания правовой регламентации.

Учитывая предназначение торгов как важного фактора развития конкуренции, основные базовые принципы, применимые к торгам во всех сферах и на всех товарных рынках, должны быть сформулированы в антимонопольном законодательстве, отраслевое же законодательство должно быть унифицировано под эти антимонопольные требования.

И в этой связи можно вновь обратиться к историческому опыту, а именно к ранее упомянутому Положению об обязательствах, заключаемых с торгов между казною и частными людьми по подрядам, поставкам, по содержанию оброчных статей и продажам казенных движимых имуществ 1830 г., которое, исходя из его содержания, а также исходя из положений ст. 1487-1500, 1504 Свода законов гражданских [10], регулировало любые торги (и торги «на закупку», и торги «на продажу») с участием казны, то есть содержало унифицированные единые положения относительно соответствующих процедур и обеспечения правил конкуренции при их организации и проведении.

\section{Литература}

1. Мейер Д.И. Русское гражданское право (в 2 ч.). По исправленному и дополненному 8-му изд., 1902. Изд. 3-е, испр. М.: Статут, 2003. С. 576.

2. Регламентъ о управлении адміралтеіства и верфи и о должностяхъ колегіи адміралтеіской и протчіх всехъ чіновъ при адміралтеістве обретающіхся. Напечатася повеленіемъ Благочестівейшаго 
Развитие правового института торгов в рамках конкурентного права

Государя Петра Великаго Імператора и Самодержцц Всероссійскаго. Въ Санктпітербургской Типографіи, апреля въ 5 день, 1722 году. С. 5.

3. Полное собрание законов Российской Империи. Собрание 2, Т. 5, Отделение 2. Спб., 1831. С. 149.

4. Беляева О.А. Торги: теоретические основы и проблемы правового регулирования. Автореф. дисс. ... докт. юрид. наук. М., 2012. С. 9.

5. Брагинский М.И., Витрянский В.В. Договорное право. Книга первая: Общие положения: Изд. 2-е, испр. М.: Статут, 2000. С. 219.

6. Гатаулина Л. Ф. Торги как способ заключения государственного и муниципального контракта // $\mathrm{KoH}-$ курентное право. 2014. №2 (использован текст, размещенный в Справочно-правовой системе КонсультантПлюс. Дата обращения: 08.01.2019).

7. Пузыревский С. А. Некоторые аспекты определения отраслевой самостоятельности конкурентного права // Юрист. 2016. № 1. С. 20-26.
8. Поленина С.В. Комплексные правовые институты и становление новых отраслей права // Известия высших учебных заведений. Правоведение. 1975. №3. С. 71-76.

9. Алексеев С.С. Проблемы теории права. Свердловск, 1972. Т. 1. С. $142-148$.

10. Сводъ законовъ Российской Империи. Т. Х.Ч.І. Санктпетербургъ. Изданіе 1900. С. 217, 220.

\section{Сведения об авторе}

Молчанов Артём Владимирович: начальник Правового управления Федеральной антимонопольной службы, преподаватель кафедры конкурентного права МГЮА им. О.Е. Кутафина

Контактная информация:

Адрес: 125993, г. Москва, ул. Садовая-Кудринская, д. 11 Тел.: +7 (499) 755-23-23, доб. 088-307

E-mail: molchanov@fas.gov.ru 